\title{
A Study of the Types of Social Trust and the Elements Influencing It: The Case of the Iranian Northern Town of Sari
}

\author{
Aboalghasem Heidarabadi \\ PhD. Candidate of Sociology, Science and Research Branch \\ Islamic Azad University, Tehran, Iran \\ E-mail: heidarabadi1977@yahoo.com \\ Bagher Sarukhani \\ Professor of Sociology, Science and Research Branch \\ Islamic Azad University, Tehran, Iran \\ E-mail: sarokhani@ut.ac.ir \\ Akbar Valadbigi \\ Islamic Azad University, Sanandaj Branch, Kurdistan, Iran \\ E-mail: karvan74@gmail.com
}

Received: June 3, 2011

doi:10.5539/ass.v8n1p183
Accepted: August 4, $2011 \quad$ Published: January 1, 2012

URL: http://dx.doi.org/10.5539/ass.v8n1p183

\begin{abstract}
This article is concerned with the level of social trust, its different types, and the social factors that influence it in the northern Iranian town of Sari, Mazandaran province. For the purpose of our study, this article adopted Giddens' and Toennies's theories as its framework to examine the theoretical issues of social trust. According to Giddens, trust comes in three types: basic, generalized, and abstract. This article, then, investigates the gesellschaft effects of the community and the economical state on the different types of social trust.

Our sample contained 320 above 20-years old residents of Sari. When validity and reliability of our questionnaire were tested, we applied survey research to collect data for analysis.

The findings indicate that low or high levels of economic state had no effect on the level of social trust in the community under study. The gesellschaft feature of that society was important in the state of social trust, as the more gesellschaft a society is, the lower generalized trust is there. It is while basic and abstract types of trust were rated high in the same society. In contrast to the other two types of trust, however, Scheffe and Duncan Tests revealed that abstract trust was of higher average.
\end{abstract}

Keywords: Social trust, Types of trust, Geselleschaft, Abstract trust

\section{Introduction}

Social trust is one of the most important elements of the contemporary life. Trust has many different meanings with more diverse significances. Sometimes, trust indicates of some aspects of social life, and often reveals some parts of personal life. Some researchers consider trust as such an important element that suggest the survival of the human societies and groups is contingent upon it. The amount of social trust differs from one society to another and various clarifications have been made in this regard. Coleman argues that trust is one of the most essential components of social capital. (Coleman, 1990: 306-7; Rahmani and Heydarabadi, 2006:170)

In the inter-personal, abstract and expert relations, however, social trust has proved to be a crucial element for progress, and on the other hand, it is necessary for social contacts development. Trust also provokes synergy and contribution and it is just in such situation that it can, in the face of the existing problems, make difference and accomplish the social contracts. Nonetheless, research has showed that there is a widening crisis in social trust 
that requires closer exploration. Social trust is a multidisciplinary concept, as it is related to, among others, sociology, social psychology, economics, management, business and organizational behavior. From the very moment we are born, we are in need of trust and it nothing but the sense we are searching in the family, school, workplace and particularly in our relationships with our peers. (Ardon and Ardon, 2009:2180)

Giddens argues that modern societies rely on the expert systems of trust, in that trust is a key element in the relationship between the individual and the expert systems. (Giddens, 2005: 52) As the recent opinion polls have indicated, societies have the lowest amount of trust in the technical and expert organizations; moreover, they have revealed that the amount of trust in the abstract organizations like the economic organizations is low. (Azimi and Edrisi, 2007: 10)

The findings of the exploratory studies show that the state of social trusts in most of the societies is not favorable. According to the Iranian scholars, too, there is evidence that confirm the decline of social trust at all levels across the Iranian society. In the international community and particularly in Iran, due to the youth of the population and being subject to the transformation eras, social trust is a necessary means for the sustainability of the social system. If the rate of trust decreases in a society, the individuals will observe some unfavorable outcomes such as: increased chaos, occupational dissatisfaction, identity crisis and social violence.

\section{Discussion}

With the development of technology and the expansion of the societies, communications have increased and people encounter a world in which they are provided with a new concept of trust. The individual human beings are subject to a global village which has turned to a small world due to the current developments. However, people of this world no longer maintain the intimate close relationships they used to hold in the past.

Putnam suggests that since the 1970s on the stock of American society's social trust has been shrinking. As the amount of those who believed that the central government is sometimes trustable or never trustable has decreased from $80 \%$ in 1966 to $75 \%$ in 1992.(Rabiee, 2006: 162-5) These days some statements are heard around which reveal a kind of crisis in the most essential compound of social capital, that is trust, and such sayings require closer examination. These statements include: one can no longer trust others, there is no authority to put the trouble of dealing with the current shortages, and truth and commitment have been removed by sycophancy.

Social trust does not have an accepted rate and state in most societies. Evidence from the industrialized and non-industrialized societies suggests that the decline of social trust results in increasing identity and personality crisis. (Giddens, 2004: 254-9)

In a research bearing the title " The factors the affect the young's values", Manuchehr Badiee has examined social trust across the cities of Mazandaran province (i.e., Sari, Babolsar, Behshahr, and Ramsar). The findings showed that the rate of social trust was low across those cities. As just $38 / 8 \%$ of the first generation (the young) reported trust in the classes of society which is a relatively low rate. The middle-aged and the older generation, however, reported 49/2\% and 39/3\%, respectively. (Pahlavan, 2006: 228)

Another survey "The values and attitudes of the Iranians", explored the state of generalized and interpersonal trust in Mazandaran province. The results indicated that the level of inter-personal in the province was low, as just $34 / 63 \%$ of the respondents reported a strong trust in family members, relatives, and friends and the rest of the participants showed a mean to low rate of trust in them. It was while the average rate of trust in family members was relatively was high $(61 / 4 \%)$, but trust in the relatives and friends was very low, as they were $23 / 2 \%$ and $19 / 3 \%$, respectively. The amount of peoples' generalized trust in some groups, organizations, and classes was very low. (The Ministry of Islamic Culture and Guidance, 2002: 205-28)

With regard to the above results, the decline of social trust in the inter-personal relationships and the institutes gives rise to some social crises. A clam, secure mutual trust can flourish the talents, and any threat to it, as the studies have shown, requires the researchers to examine the factors that create such situation in order to determine the shortages and make grounds for strengthening social trust. The level of trust has been so low in some societies that scholars like Putnam has introduced the theory of declining trust. (Putnam, 1995)

Therefore, social trust and its low level in Mazandaran province and Sari city is worth to be surveyed as a social problem. (The Ministry of Islamic Culture and Guidance, 2002; Pahlavan, 2006; Share'apour, 2007) So, the current paper seeks to identify, analyze, and clarify the many social factors that influence trust in Sari city. 


\section{Theoretical framework}

As one of the vital aspects of human relationships, social trust makes grounds for cooperation among the members of society. It accelerates engagement in different arras including economic, social, political, and cultural spheres and therefore, individuals are more apt to have cooperation with other groups.

According to Giddens, in the pre-modern societies, trust was not as much a matter of importance as it is in the modern societies. As when people have more spatial-temporal distance from each other, more trust is needed.

With their local and native characteristics, the pre-modern societies had mutual interactions at a local level and there was such a transparency in the relationships that trust was not so lacking, as one can feel such trust naturally. However, in the extended and developed societies which are characterized by social relationships at far away spatial-temporal distances and there is fewer face-to-face relations among the individuals, they need to create trust through legal and monetary systems. (Ritzer, 2001: 822)

Social trust is an impetus which motivates people to form mutual and diverse relations with each other. This component is so vital that some scholars have suggested that it is a sense that leads to cooperation and it is just in such situation that, in the face of the current problems, people can solve their troubles. Even some believe that it is the most important facet of social capital which influences other aspects of it. It has also been evaluated at different levels such as: trust in self, family, friends, formal and informal institutions, and social institutions.

Both at micro-and macro-levels, social trust brings negative and positive senses in individuals and it can be studied through taking psychological and sociological approaches. The psychological approach, however, treats trust as a personal characteristic and emphasizes on the role of personal emotions. The sociological approach, on the other hand, considers trust as a feature of social relationships or system. The outcome of these two different approaches is a synthetic attitude.

A crucial variable which affects the sense of security is social capital and its main components, social trust. Trust is considered to be the most important element in discipline and order and it has a pivotal position in the works of Durkheim and Tonnies. Some suggest increasing social trust through micro-level and brokerage groups, where trust is built and developed.

Pioter Sztomka (2003) in his review of the literature has treated the vital aspect of trust. In his opinion, there are some unique features in the contemporary societies which highlight the importance of social trust. As one can no longer consider living in the modern world without trust, and therefore, building and maintaining trust has become an inevitable necessity. In short, he believes that the importance of social trust and having trust in the others is related to the following elements: the presence of a strong mutual dependency, futurism, increased complexity in roles and the expansion of social relationships, unpredictability of life, the necessity of making choice among different actions, encountering the dark sides of social environment, individuals' increasing autonomy and finally, the presence of unfamiliar individuals around. (2007: 26-31)

Coleman (1998) argues that social trust is one of the underlying features of social capital and mutual social relationships. Trust also facilitates communication and interaction in economic, social, cultural, and political arenas, and among its advantages one can refer to the prosperity of social life. Having trust in the daily interactions brings stability in social capital and national integrity. As any decline in the sense of trust results in crisis in integrity and rupture in national unity. (Coleman, 1998: 28)

According to the pragmatic sociologist, however, if people identify with their society and form and emotional bond with the greater "We", then they will behave more sympathetically. Social relationships for these people will no longer understood as only satisfying their material and personal needs. They will not regard their peers as competitor or enemy, rather they feel security by living among them and it is when this process brings mutual trust and sustains it.

Once the greater "We" is built, people are more ethical, feel obligation toward their society and treat others with more benevolence. This sense of obligation is due to the internal obligations rather than the external ones. Here the ethical actions are done voluntarily, and the range of this "We" can be extended from family to the whole nation. The function of this "We", then, can differ based on time and place. (Chalabi, 1996: 69)

Trust is one of the key concepts in the social science, and particularly in sociology. This concept has been pivotal in the thoughts of the classic sociologists including: Durkheim, Zimmel, Tonnies, and Weber and also among the contemporary sociologists like Parsons, Giddens, Ufeh, Sztomka, Coleman, Fukuyama, and Putnam. These sociologists have examined social trust in their discussions on the sociological theories. This concept has been so important to these scholars that they have studied it from one point of view. Like any key concept in the social 
sciences, social trust is subject to such a complexity that each theory has been devoted to one aspect of the term. In sum, the proposed theories on trust can be classified into three groups: micro-, middle-, and macro-level.

In micro-level which is centered on inter-personal trust, the aim is to investigate the micro, personal elements. Researchers on this approach emphasize action as the basis in investigating and analyzing the concept of social trust. Erikson, Coleman, Pieter Blaw, and Johnson, among others, have adopted this level to study social trust.

At the heart of the middle-level studies, however, stands Giddens as a pioneer who believes that trust in the pre-modern systems has had a face-to-face co-present nature, while in the contemporary era, it is not the case. Our impersonal trust in the unfamiliar others is the result of the increasing nature of the abstract systems. A major characteristic of trust in the modern time, therefore, is a faceless commitment which gets rise within expert systems. (Riters, 2001: 768)

At the macro-level, scholars like Durkheim, Parsons, Ingelheart, Tonnies, and Fukuyama have studies social trust by emphasizing the social construct of society. In investigating social trust, they have focused their studies on the social construct of society and conceptualized trust as a feature of social relationships or a collective characteristic as a whole. (Ojaghloo and Zahedi, 2005: 99) Later on, this paper will treat theories of Tonnies(macro-level) and Giddens(middle-level) which have been adopted as the theoretical framework and analytical model of our study.

\section{Ferdinand Tonnies}

Based on the social structures and the way mutual social relations take place, Tonnies has distinguished two different types of society: Gemeinschaft (community) and Gesellschaft (society). He asserts that one can observe elements of gemeinschaft and gesellschaft in any society. Tonnies argue that in the gemeinschaft communities "we" prevails "I". A characteristic of gemeinschaft is intimate, private, and exclusive life with others. In the community, from the moment one is born, he/she is obligated to respect all the rules of that community. In contrast, in the gesellschaft, however, individualism and monetary relationship is regarded $\mathrm{s}$ the main characteristic. The gesellschaft world is a Hobbesian one, where one does not accept others as the members of that society, rather regard them as a means to accomplish his ends with.( Azkia and Ghafari, 2005:156)

According to Tonnies, the trust-based relationships just can be observed in the gemeinschaft. Trust is an end taking place within the social context and gemeinschaft economy. The trust-based relationships and trustworthy individuals, at the other hand, are just present in the natural community. One trusts his family members and friends as his sense is based on the similarities and mutual understanding and this process is consistently enriched by the common activities and experiences. Trust is the core concept of social integrity that is strengthened by the religious and ethical values, and trust in turn, facilitates trust relations and increases social integrity. In the traditional communities or gemeinschaft, like respect and the sense of personal assets, trust is a virtue; however, in gesellschaft, trust is treated as an impersonal formal asset.

Tonnies observes writes that:" competition is a component that flows actively in the gesellschaft which is ruled by individualism. As each individual is left single and a counter-tension exist among the individuals. The areas of activity and power are segregated strictly. As each individual rejects the other and intervening in the realm of others is understood as violation and inimical act. (Azkia and Ghafari, 2005:156)

Furthermore, in the gesellschaft society, people are in a strict competition with each other over personal interests, and as a result there is no sign of a shared sentiment which can hold the members of society to each other. In such a society, therefore, the social integrity of people is an organic one and individualism rages all the time. The wayward conservative members of such a society can no longer be trusted by others or they themselves cannot trust others. As each individual requires the assets of the other to satisfy his/her needs, and this result in an instrumental unreliable relationship.

There is a kind of will similar to instrumental objective intellect in the gesellschaft society. Tonnies asserts that gesellschaft relations are based on individualism and lack of mutual trust, and in such a society, then, everyone strives for his interests and refuses to make contact with others. Isenshtad suggests that the most important component of social order for scholars like Durkheim and Tonnies is social trust and integrity. (Chalabi, 1996: 12) That is maintaining social order is impossible without trust and integrity. Without considering social trust, maintaining and strengthening social order is impossible in the gesellschaft society, where individuals' integrity is organic.

To sum it up, a kind of personal mutual trust rules in the gemeinschaft community and social integrity is of a mechanical nature. In this kind of community, at the other hand, some sorts of generalistic and personal integrity exist in this community. In contrast, organic integrity is found in the gesellschaft society which focuses on 
abstract trust. Here integrity is organic and benefit-oriented particularistic relationships exist in this society. In other words, objective trust is widespread in the gemeinschaft community; however, subjective trust is the main type of trust in the gesellschaft society. Based on the theory of Tonnies, we can here conclude that the amount of trust is shrinking in the gesellschaft societies.

\section{Antony Giddens}

According to Giddens, the societies of our time need trust in order to develop. The concept of trust, however, not only consists of having trust in a certain individual, but also having trust in the larger institutes, such as the specialized organizations. Such relationships, however, have not existed in the past. Trust appears at different levels as the basis of our daily decision-makings. But, having trust is not always the result of conscious decision-makings. Inclination toward trust is in direct relationship with the mental security of the individuals and groups in relation with certain achievements or special individuals and organizations.

Giddens defines trust as "having trust in the trustworthiness of the individuals or organizations with regard to a series of consequences or incidents where this trust expresses having trust in the honesty or love of others or the accuracy of technical knowledge. (Giddens, 1988: 34) Not only trust has a comprehensive importance in modern societies, but it also contributes to the symbols and expert organizations that are at the disposal of the modern rootless life, in order for the financial organizations and legal systems to be effective in the society, it is for the members of society to have trust in them. (Ritzer, 2001:768)

Trust differs with the kind of confidence that is common in the formal exchanges that are called by Zimmel as "weak inductive knowledge". Some sorts of decision-makings are based on the inductive outcomes of the experiences from the past which are supposed to be valid for the present. This confidence can be an ingredient of trust; however, it is not enough for building a trust-based relationship. Trust is a mutation in the atmosphere of obligation; in other words, trust is a authentic understandable quality which has direct relationship with disappearance in time and place or unawareness. (Giddens, 2004:38-39)

According to Giddens, trust is a vital phenomenon in the development of personality which has a unique connection with different disembodying and abstract systems. In its general appearance, trust has direct relations with the sense of ontological security.

At the other hand, trust is a means for interaction with the abstract systems which simultaneously evacuate the traditional contents of the daily life and accelerate the effects of globalization. Trust, therefore, produces mutation to the depth of faith and confidence that are essential to the practical obligations. Trust is a crucial necessity for the protective cocoon which self requires for its encounters with the daily realities. (Giddens, 2004:18)

Giddens also distinguishes between two types of trust: trust in certain individuals and trust in the abstract individuals or organizations. Abstract trust, however, encompasses awareness of the risks of the trusted individuals. While the actor evaluates the value of his trust in certain individuals, he can also gain ideas about having trust in the generalized others which is based on their history, potentials, and motivations. (Shara'apour, 2001:104) One can also have ideas regarding the value of trusting the abstract systems, for example institutes. This process can also be called "the institutional level of trust", and this is what Giddens calls " trusting the expert systems". That is, one may not know those who have contributed to building his house or car, but he may have some sorts of trust in their standards, regulations, control of quality, and supervisions. (Shara'apour, 2001:104)

Basic trust is essentially related to the formation of time and place among different individuals. This type of trust is having trust in the objective tangible world and durability of others that stems from the experiences of early life. (Giddens, 2004:323) Establishing basic trust is critical in providing personal identity and is of great importance in building relationship between daily life and the normal appearances of individuals.

Furthermore, Giddens believes that basic trust functions as a means to remove the risky phenomena from the scene of daily life. We accept the way individuals apparently behave and who they are due to basic trust; we, too, behave the same as what we observe of others. (Giddens, 2004:181) according to Giddens, trust is the inevitable way of social life and a component of modernity. In the traditional cultures, however, four local areas including kinship, local community, tradition, and religious cosmology are in distinctive relation with trust.

Giddens argues that the main sources of trust of the traditional societies no longer hold their importance in the modern ones. He asserts that a genuine relationship is dependent on a close relationship with intimacy. If one wants to build trust, he should trust the other side and he himself be trusted in the context of his relationship. 
Maintaining the authenticity of this intimate relationship requires us to consider the same balance that we hold between autonomy and integrating with the other side.

A point in building and developing trust in the genuine relationships is that everyone should recognize the other side and be able to extract favorite responses from his sayings and behaviors. (Giddens, 1999:141) To Giddens, not only trust in the pre-modern and modern societies is different, but also it is contradictory. To put it differently, one can refer to the environments of trust and risk about the cultures of these societies. In the pre-modern era, however, local trust was very important, and this reveals the public backgrounds and the general orientation of trust in such societies. In the modern societies, at the other hand, trust has declined among individuals and its general orientation is based on the relationship between trust in the abstract systems and the expert ones, which according to Giddens, are characterized with disembedment and rootlessness in the modern world.

In contrast to modern society, in the pre-modern society the distance between time and place is lesser; therefore, trust and risk can be investigated in the local situation of place. In the pre-modern world, ontological security should be conceived in relation with the environments of trust and forms of risk that exist in the local situation of place. Due to the internal connection between trust and lack of presence, it relies on the methods of arranging the trustworthy co-actors in time and place. (Giddens, 2005:120)

The results of Giddens's researches in England reveal that social trust has three dimensions: basic trust, interpersonal mutual trust, and abstract trust. In other words, trust can appear in three different shapes: interpersonal, trust in the relatives; social or generalized trust, trust in the strangers; and finally, civic trust, which is trust in the organizations and institutes.

\section{Methodology}

Survey study was adopted as the methodology of the present study. This approach focuses on making hypothesis and identifying the relationships among the variables. In contrast to the experimental methods where the researcher manipulates the variables, in survey the researcher selects the variables for evaluating their amount of validity and reliability. Therefore, this study deals with statistical samples which have been taken with special methods from the original society. Survey study chooses a large population and takes its intended sample from it to discover the relative amount of distributing sociological and psychological relationships. In its academic sense, this method was introduced into the social sciences in the $20^{\text {th }}$ century. (Kerlinger, 1997: 77)

On the other hand, a survey researcher seeks to identify the causes of the social phenomena through examining the variables and other characteristics which are regularly involved in it. The advantage of this approach is having a large body of samples which makes the generalization of its results more likely. Thus, this method allows the researcher to quantify the data and examine the correlations among them.

With regard to our facilities, personnel, and expenses involved in completing the questionnaires and conducting the interviews, we used Cochran formula to determine our sample size. As a result, our sample size was fixed at 320 people. Our sampling method was integrative sampling in two ways: simple random and quota method. In order to study the meaningfulness of the relationship among the variables, we applied variance analysis and multi-variable regression. Path analysis, however, was conducted to determine the impacts of the independent variables on our dependent variable. After collecting, editing, and processing our data, we analyzed them by SPSS.

With regard to validity, we adopted face validity which is based on the judgments of the experts. That is, we determined the validity of our research's indicators through asking the opinions of the referees. (Rafi'apour, 2003: 142) Validity refers to the adaptation between the conceptual and operational definitions of a variable. Therefore, validity deals with the question that "Does the researcher really measure what he thinks he is measuring?" Our proposed questionnaire, in which we tried to include every variable that were to be measured, was revised several times and after primary testing and revising the items, our final questionnaire was prepared.

If a test or an analysis is done several times, and all the results are the same, then it is said that the findings are academically valid. By reliability we mean obtaining the same results by conducting a test. (Sarokhani, 1998: 146) So, reliability shows the rate of our precision in measurement. Cronbach's Alpha is often adopted in survey studies. In the present paper, we took a pre-test of 30 Sari residents to determine the reliability of all types of trust (i.e., basic, generalized, and abstract) and the Gesellschaft society. Table 1 summarizes the final Cronbach's Alpha which indicates of the correlation among the items.

$<$ Insert Table 1 here $>$ 


\section{Research hypotheses}

- In the society under study, basic trust is lower that other types of trust;

- The higher the economic state of a society, the richer its stock of social trust; and

- The gesellschaft features of a society entail trust shrinking.

\section{The definition of our variables}

\subsection{Social trust}

It is a concept which rises in the process of social relationships among the individuals and social organizations. As a social phenomenon, trust is a variable which is the result of confidence with the individuals, patterns, social structures, and roles. So, trust is sincerity in the other part's acts and statements. Giddens argues that trust is reliance on the personal nature of an individual or authenticity of his/her statements. (Amirkafi, 2011:11)

According to Giddens, trust is of three types: basic, generalized, and abstract. It is not easy to define trust; however, various works have dealt with it. It has been considered as in relation with concepts like tolerance, sincerity, interaction, solidarity, and brotherhood. (Newton, 2001: 203) Generalized trust includes our trust in the family members, peers, neighbors, the government, and social organizations. (Gliser, 2000; Newton, 2001; Delly, 2002)

Chalabi argues that if the social relationships increase in a society, the administrative expenses and the additional guarantees of the social relationships' organization will decrease. So, one can suggest that cooperation, synergy, and social unity increase in the daily affairs. Therefore, this kind of social commitment serves as a mechanism to arrange the expectations, behaviors, and actions of the individuals. (1996: 88)

Generally trust is divided into three types: basic, generalized, and abstract.

\subsection{Basic trust}

It is the attitude of the individual toward himself/herself and his/her surrounding. It is also the result of the early life experiences. This type of trust is built and generalized in the earlier stages of socialization and is characterized by features such as: having security and relax with the family and friends, holding positive attitudes toward life, and occupational satisfaction.

\subsection{Generalized trust}

In this type of trust, based on one's knowledge of others, he/she trusts them. In other words, one relies on his/her knowledge of others. Generalized trust can be realized through trusting colleagues, townsfolk, peers, relatives, and external individuals.

\subsection{Abstract trust}

According to Giddens, rich in this type of trust are those individuals who enjoy an industrialized life, higher education, urbanity, and belong to the higher classes. (2004) It can be operationalzed through indicators such as trust in the social institutes, different groups including doctors, judges, lawyers, police, and artists.

\subsection{Gesellschaft society}

It is a type of society in which people only engage in relationship with others just to fulfill their instrumental ends. Tonnies believes that gesellschaft relationships are individualistic and based on distrust. In this society, therefore, everyone adheres to his/her interests and avoids making contact with others. (Girouche, 1997:43) Such a society is characterized by individualism, competition, preference of duties, organic solidarity, and personal privacy.

\subsection{Economic state of society}

This variable was defined and evaluated for our respondents through indicators like literacy, job, income, and household expenses.

\section{Findings}

Our findings indicated that the average of social trust in the society under study was $106 / 8$. The highest and lowest rates of trust being 261 and 55, respectively and the change range of trust was 206 . We used quarters and quarter distribution to study the rate of social trust and to determine how many people had the lowest and highest rates of trust.

$<$ Insert Table 2 here $>$ 
The amount of individuals in the fourth quartile (high social trust) and the first quartile (low social trust) was lower relative to the sum of the second and third quartiles (average social trust). 50/3\% of the respondents reported mean trust; $25 / 6 \%$ a low rate of trust, and $24 / 1 \%$ a high rate of trust.

There was also a meaningful relationship between social trust and cultural development in Mazandaran province, as by increasing social trust, culture will develop more rapidly. There was a direct relationship between these two variables and the significance of the three statistics (Kendall tau, Spearman, and Samersday) was at 95\%. (Rahmani and Heydarabadi, 2009: 228 and 231)

$<$ Insert Table 3 here $>$

In this research, the economic state was measured at ordinal measurement level and other variables were tested at a virtual spatial level. With respect to the correlation coefficients of Spearman, Kendall tau, and Pierson between the independent variables and the dependent one, we can conclude that there was no correlation between the economic state and social trust; however, there was correlation and a direct positive relationship between our independent variables and the dependent variable which can be observed in Table 4.

$<$ Insert Table 4 here $>$

The results of regression analysis showed that $80 / 6 \%$ of the changes in social trust were explained by our independent variables. In other words, with regard to the determination coefficient, just $20 \%$ of the changes was left unexplained and decided to be dependent on other elements. The multiple correlation coefficient was $89 / 8 \%$ and high whenever indicates of the strong relationship between trust and the independent variables.

The table of variance analysis reveals the significance of regression and the existence of a lineal relationship between the variables which attests the level of their significance. The main results of regression can be seen in the table of coefficients. In this table, column B is used as the regression coefficients to anticipate the amount of social trust in regression equation. In this table, standard error, the standardized values of $\beta$, values of $t$-test. And significance level of each variable is presented. As the value of meaningfulness reveals, economic state, among others, was meaningless and the impacts of other variables were meaningful and influenced the anticipation of the dependent variable at a high level. $\beta$-values indicate that the variables of generalized, basic, and abstract trust and gesellschaft society had the highest influence on social trust.

$<$ Insert Table 5 here $>$

$<$ Insert Table 6 here $>$

$<$ Insert Figure 1 here $>$

In the society under study, however, different types of trust varied with each other and therefore their averages were different. The average of basic trust was $16 / 8 \%$; generalized trust held an average of $15 / 05 \%$, and abstract trust had an average of $74 / 9 \%$.

In order to contrast the different types of trust, we applied F-test and average contrast which was meaningful $(0 / 000)$. To get a clearer view of the differences among the types of trust, Scheffe and Duncan tests were conducted. Scheffe test showed that the difference between basic and abstract trust and generalized and abstract trust was meaningful. However, there was not a meaningful difference between the average of basic and generalized trust.

\section{Conclusion}

Social trust is one of the most important elements of the contemporary life. Trust has many different meanings with more diverse significances. Sometimes, trust indicates of some aspects of social life, and often reveals some parts of personal life. Some researchers consider trust as such an important element that suggest the survival of the human societies and groups is contingent upon it. This paper reviewed the theories of sociological figures such as Giddens, Sztompka, and Tonnies on trust. For Giddens, among others, trust was of three types: basic, abstract, and generalized.

This article argued that as the strongest mechanism in making balance in society, social trust is influential just once it is not confined to the face-to-face relationships. This paper found that the rate of social trust in Sari city, the society under study, was low. In this research, applied survey method to measure the influences of some social variables on trust and found that gesselschaft society had the highest rate of influence; however, the economic state of the society had the minimal influence on it.

In Sari city, trust in the abstract systems has been formed as a means for establishing the relationships and this process is in the unlimited spatial-temporal ranges. In the rural areas, this type of trust can no longer sustain, as 
they are predominated by traditionalism. In sum, a type of trust which is peculiar to the modern industrialized societies and is characterized by having trust in the social organizations and institutes has been established in Sari. Having this in mind, we can claim that in the society under study, the abstract and expert trust is more common than other types of trust.

\section{References}

Amirkafi, Mehdi. (2001). Social trust and the elements influencing it. Research Index, Vol. 18. Ministry of Islamic Culture and Guidance.

Azkia, Mostafa and Gholam Reza Ghafari. (2005). Sociology of development. Tehran: Kryhan Press.

Chalabi, Masa'oud. (1996). Sociology of order. Tehran: Ney Press.

Coleman, James. (1998). Principals of social theory. Tehran; Ney Press.

Giddens, Antony. (1990). The consequences of modernity. Tehran: Markaz Press.

Giddens, Antony. (1999). Sociology. Tehran: Ney Press.

Ministry of Islamic Culture and Guidance. (2002). Iranians' values and attitudes. Tehran.

Newton, Kenneth. (2001). Trust, social capital, civil society, and democracy. International Political Science Review, Vol. 22, No. 2, pp.201-214. http://dx.doi.org/10.1177/0192512101222004

Ojaghloo, Sadjad and Mohammad Javad Zahedi. The study of social trust and the elements influencing it among Zanjanian citizens. Journal of Iranian Sociology, Vol. 6, No. 4, pp.92-125.

Pahlavan, Manouchehr. (2006). The study of the social elements which influence values change among the young. PhD. Dissertation for sociology. Tehran Islamic Azad University.

Putnam, Robert. (1995). Bowling along Americans; declining social capital. Journal of Democracy, Vol. 6, No. 1, pp.65-75. http://dx.doi.org/10.1353/jod.1995.0002

Riters, George. (2001). Theory of sociology in the contemporary era. Tehran: Elmi Press.

Sarukhani, Bagher. (1998). Research methods in the social sciences. Tehran: The humanities and cultural studies center Publications.

Share'apour, Mahmoud. (2001). Erosion of social trust and its consequences. Sociological Association Newsletter, Vol. 1.

Sztompka, Pioter. (2007). Trust: a sociological theory. Tehran: Tirajeh Press.

Table 1. Reliability of the research's variables

\begin{tabular}{|c|c|c|}
\hline Variables & Number of items & Cronbach's Alfa Coefficient \\
\hline Basic trust & 9 & $0 / 68$ \\
\hline Generalized trust & 10 & $0 / 78$ \\
\hline Abstract trust & 8 & $0 / 72$ \\
\hline Gesellschaft society & 12 & $0 / 88$ \\
\hline
\end{tabular}

Table 2. Quartiles of social trust scores

\begin{tabular}{|c|c|c|c|}
\hline Quartiles & Frequency & Percentage & Score of social trust \\
\hline First & 82 & $25 / 6$ & $\leq 30 / 3$ \\
\hline Second and third & 161 & $50 / 3$ & $30 / 4-36$ \\
\hline Fourth & 77 & $24 / 1$ & $\geq 36 / 1$ \\
\hline Total & 320 & 100 & - \\
\hline
\end{tabular}


Table 3. Mean and standard deviation of the variables of the research

\begin{tabular}{|c|c|c|c|c|}
\hline Variable & Mean & Min & Max & SE \\
\hline Basic trust & $16 / 83$ & 5 & 166 & $2 / 15$ \\
\hline Generalized trust & $15 / 05$ & 8 & 21 & $38 / 78$ \\
\hline Abstract trust & $74 / 9$ & 34 & 234 & $42 / 51$ \\
\hline Social trust & $106 / 8$ & 55 & 261 & $104 / 21$ \\
\hline Gesellschaft society & $70 / 6$ & 48 & 178 & \\
\hline
\end{tabular}

Table 4. Correlation coefficients of the independent variables

\begin{tabular}{|c|c|c|c|c|}
\hline Variable & $\begin{array}{c}\text { Correlation } \\
\text { coefficient }\end{array}$ & $\begin{array}{c}\text { Correlation } \\
\text { coefficient value }\end{array}$ & Sig & Relationship \\
\hline $\begin{array}{c}\text { Socio-economic } \\
\text { state }\end{array}$ & Spearman & $-0 / 061$ & $0 / 276$ & No \\
\hline $\begin{array}{c}\text { Socio-economic } \\
\text { state }\end{array}$ & Kendall tau & $-0 / 052$ & $0 / 280$ & Positive and direct \\
\hline Generalized trust & Pearson & $0 / 608$ & $0 / 000$ & Positive and direct \\
\hline Basic trust & Pearson & $0 / 556$ & $0 / 000$ & Positive and direct \\
\hline Abstract trust & Pearson & $0 / 595$ & $0 / 000$ & Positive and direct \\
\hline Gesellschaft society & Pearson & $0 / 309$ & $0 / 000$ & \\
\hline
\end{tabular}

Table 5. Multiple and determination coefficients

\begin{tabular}{|c|c|c|c|}
\hline $\begin{array}{c}\text { Multiple correlation } \\
\text { coefficient }\end{array}$ & Determination coefficient & Revised coefficient & Standard error \\
\hline $0 / 898$ & $0 / 806$ & $0 / 803$ & $0 / 510$ \\
\hline
\end{tabular}

Where $\mathrm{F}=5 / 261$ and $\mathrm{Sig}=0 / 000$.

Table 6. Regression coefficients of the independent variables

\begin{tabular}{|c|c|c|c|c|c|}
\hline Variables & $\begin{array}{c}\text { Regression } \\
\text { coefficient }\end{array}$ & SE & B-value & t-test & sig \\
\hline Fixed value & $-1 / 089$ & $0 / 151$ & - & $-7 / 202$ & $0 / 000$ \\
\hline $\begin{array}{c}\text { Socio-economic } \\
\text { state }\end{array}$ & $-0 / 004$ & $0 / 040$ & $-0 / 002$ & $-0 / 094$ & $0 / 925$ \\
\hline Basic trust & $0 / 453$ & $0 / 028$ & $0 / 412$ & $16 / 192$ & $0 / 000$ \\
\hline Abstract trust & $0 / 431$ & $0 / 026$ & $0 / 436$ & $16 / 792$ & $0 / 000$ \\
\hline $\begin{array}{c}\text { Generalized } \\
\text { trust }\end{array}$ & $0 / 448$ & $0 / 025$ & $0 / 461$ & $18 / 126$ & $0 / 000$ \\
\hline $\begin{array}{c}\text { Gesellschaft } \\
\text { society }\end{array}$ & $0 / 110$ & $0 / 024$ & $0 / 120$ & $4 / 622$ & $0 / 000$ \\
\hline
\end{tabular}




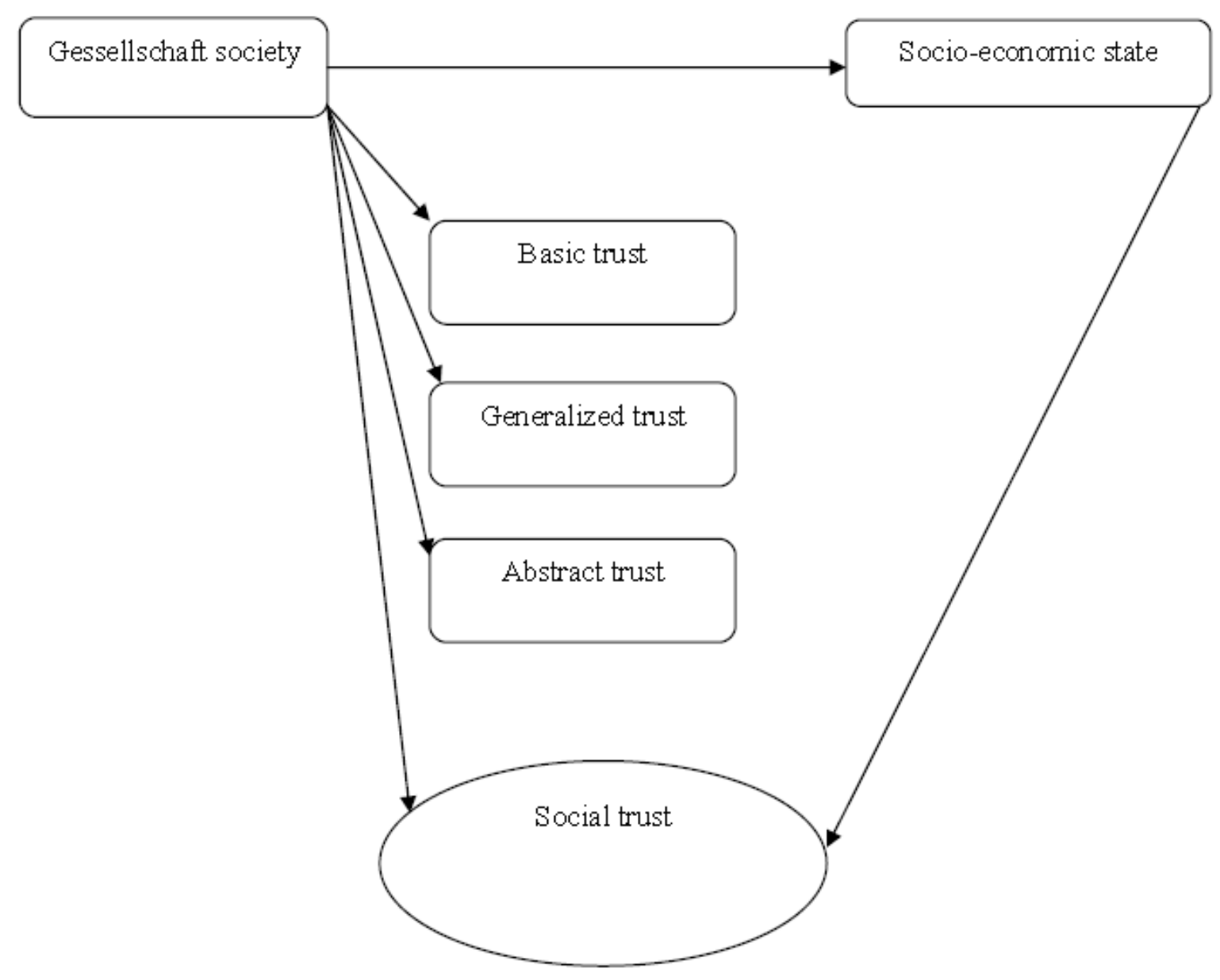

Figure 1. Analytical model of the research 